\title{
PERENCANAAN TEKNOLOGI PEMANENAN AIR HUJAN SEBAGAI SUMBER AIR BERSIH PADA MASJID AGUNG BANJARBARU KALIMANTAN SELATAN
}

\author{
Endah Lestari ${ }^{1}$, Buddy Pamuji ${ }^{2}$ \\ ${ }^{1}$ Jurusan Teknik Sipil, Universitas Tarumanagara, Jakarta \\ Email:endahzenjankoka@gmail.com \\ ${ }^{2}$ Arsitek, PT. Aera Karya Kontraktor, Jakarta \\ Email: buddypamuji@gmail.com
}

\begin{abstract}
ABSTRAK
Bencana kekeringan yang terjadi akhir-akhir ini menimbulkan berbagai jenis penyakit, rawan pangan dan menurunnya pasokan air bersih yang merupakan kebutuhan utama manusia. Kekeringan sebagian besar diakibatkan oleh gangguan keseimbangan hidrologis seperti terjadinya degradasi aliran sungai yang beralih fungsi yang menyebabkan terganggunya sistem peresapan air tanah dan pendangkalan waduk atau tempat penampungan air yang menyebabkan daya tampungnya menurun.Pendangkalan tersebut akan membuat cadangan air yang tersimpan menjadi lebih sedikit untuk persediaan air di musim kemarau.Kalimantan Selatan termasuk daerah yang memiliki ancaman persoalan kelangkaan air bersih terutama di wilayah Banjarmasin.Dalam penelitian ini penulismerencanakan penerapan teknologi pemanenan air hujan pada Masjid Agung Banjarbaru Kalimantan Selatan sebagai salah satu cara untuk memenuhi kebutuhan air baku jamaah dalam kegiatannya di lingkungan Masjid Agung. Metode yang digunakan adalah pengumpulan data dan pengolahan data. Dari hasil perhitungan jumlah volume curah hujan yang di dapat melalui atap bangunan, menunjukkan bahwa Volume air yang dihasilkan oleh hujan adalah $1.785,60 \mathrm{~m}^{3}$. Sedangkan kebutuhan air baku setiap bulannya dihasilkan sebesar 1.350m ${ }^{3}$.Volume suplai air hujan > dari volume kebutuhan air. Sehingga dapat disimpulkan bahwa air hujan dianggap dapat memenuhi kebutuhan air bersih pada kawasan tersebut. Melalui kolam-kolam penampungan air hujan yang juga berfungsi sebagai elemen estetika bagi bangunan, air hujan dialirkan ke ruang-ruang wudhu dan kamar mandi. Kolam pemanenan air hujan yang direncanakan berjumlah 4 buah, di setiap kolam diharapkan dapat menampung volume tampungan air hujan sebesar>446, $40 \mathrm{~m}^{3}$.
\end{abstract}

Kata kunci: air bersih, air hujan, penampungan air hujan, penampungan air hujan dari atap

\section{PENDAHULUAN}

\section{Latar Belakang}

Dalam beberapa dekade terakhir bencana kekeringan berlangsung di berbagai tempat di Indonesia, khususnya terjadi di daerah pertanian dan tambak. Dampak terbesar yang dialami adalah kerawanan akan pangan karena hasil produksi panen padi dan sayuran menurun bahkan sering mengalami gagal panen. Keterbatasan sumber daya alam akan mengganggu perekonomian masyarakat. Bencana kekeringan menimbulkan berbagai jenis penyakit dan mengganggu keseimbangan ekosistem alam, seperti kebakaran hutan dan rusaknya ekosistem air. Disisi lain kekeringan dapat menyebabkan berkurangnya pasokan air bersih yang dibutuhkan bagi penduduk di wilayah tersebut.

Kekeringan yang terjadi diakibatkan oleh penyimpangan iklim, gangguan keseimbangan hidrologis dan kekeringan agronomis. Akibat yang paling berpengaruh terhadap kekeringan adalah masalah gangguan keseimbangan hidrologis seperti terjadinya degradasi aliran sungai yang beralih fungsi yang menyebabkan terganggunya sistem peresapan air tanah dan pendangkalan waduk atau tempat penampungan air yang menyebabkan daya tampungnya menurun. Pendangkalan tersebut akan membuat cadangan air yang tersimpan menjadi lebih sedikit untuk persediaan air di musim kemarau.Penggunaan sumber air tanah secara berlebihan dengan cara sumur pompa tangan, pompa mekanik dan lain sebagainya menyebabkan persediaan air tanah berkurang secara drastis. Bukan itu saja, masalah yang utama adalah dengan tidak 
adanya usaha-usaha pengisian ulang akuifer secara kontinyu. Hal tersebut menyebabkan muka air tanah (Ground Water Table) akan semakin masuk lebih dalam.

Kalimantan Selatan memiliki ancaman persoalan kelangkaan air bersih terutama di wilayah Banjarmasin. Kasus terjadi pada pertengahan Januari 2014 lalu tiba-tiba air Sungai Martapura yang membelah kota Banjarmasin Kalimantan Selatan berubah warna menjadi keruh pekat dan kuning kemerahan. Kondisi air demikian mengisyaratkan air sungai yang berhulu di Pegunungan Meratus tersebut sudah terkontaminasi kandungan partikel atau kandungan lumpur yang jumlahnya melimpah ruah. Dengan adanya kandungan partikel dalam air Sungai Martapura tersebut sudah membuktikan kawasan resapan air di hulu mengalami kerusakan resapan air yang parah. Kerusakan resapan air diduga akibat penggundulan hutan, penebangan kayu, pertambangan emas, pertambangan biji besi, atau bahkan belakangan kian marak adalah pertambangan batu bara.

Pada penelitian kali ini penulis merencanakan penerapan teknologi pemanenan air hujan untuk memenuhi kebutuhan air bakupada desain Masjid Agung Banjarbaru Kalimantan Selatan. Desain Masjid Agung Bajarbaru ini telah diikutsertakan pada "Sayembara Desain Masjid Agung Kawasan Perkantoran Banjarbaru" yang dilaksanakan oleh Dinas Pekerjaan Umum dan Penataan Ruang Pemerintah Provinsi Kalimantan Selatan pada tanggal 26 April 2017.

\section{METODE PENELITIAN}

\section{Lokasi Penelitian}

Lokasi pembangunan Masjid Agung berada di kawasan perkantoran Kota Banjarbaru yang merupakan sebuah kota yang baru dalam wilayah Provinsi Kalimantan Selatan. Kota Banjarbaru Kota Banjarbaru memiliki luas wilayah $371,30 \mathrm{~km}^{2}$ (37.130 ha) yang terbagi atas 5 kecamatan dan 12 kelurahan.Terletak pada koordinat $03^{\circ} 27^{\prime} \mathrm{s} / \mathrm{d} 03^{\circ} 29^{\prime} \mathrm{LS}$ dan $114^{\circ} 45^{\prime} \mathrm{s} / \mathrm{d} 114^{\circ} 45^{\prime} \mathrm{BT}$. Posisi geografis Kota Banjarbaru terhadap Kota Banjarmasin adalah $35 \mathrm{~km}$ pada arah 296 $30^{\prime}$ sebelah tenggara Kota Banjarmasin, sedangkan posisi terhadap Martapura, Kabupaten Banjar adalah $5 \mathrm{~km}$ pada arah $55^{\circ} 30^{\prime}$ sebelah barat daya Kota Martapura.

Luas lahan pembangungan Masjid Agung adalah \pm 11 Ha (termasuk embung dan area parkir) dengan lahan berbentuk lingkaran. Lokasi rencana pembangunan Masjid Agung yang terletak di jalan Jl. Dharma Praja, Kawasan Perkantoran Pemerintah Provinsi Kalimantan Selatan di Banjarbaru ditunjukkan pada gambar 1.

\section{Metode Perencanaan}

Perencanaan ini meliputi aspek teknis, yaitu rancangan desain pemanenan air hujan pada Masjid Agung yang berupa desain bak penampungan air hujan dan perencanaan system penyaluran air hujan.

\section{Pengumpulan Data}

Tahap pengumpulan data yang terdiri dari data primer yaitu mengenai kondisi lahan dan area di lokasi pembangunan Masjid Agung Banjarbaru yang memungkinkan dijadikan area penangkapan dan penampungan air hujan, data sistem penyediaan air bersih eksisting di lingkungan proyek pembangunan dan data sistem kebutuhan air bersih per orang per hari pada sektor non domestik dalam hal ini tempat peribadatan. Data sekunder adalah data kapasitas jamaah yang dapat ditampung pada bangunan Masjid Agung, denah dan luas rencana bangunan 
Masjid Agung, peta lokasi dan rencana site plan Masjid Agung, dan data curah hujan selama 10 tahun terakhir dari BMG.

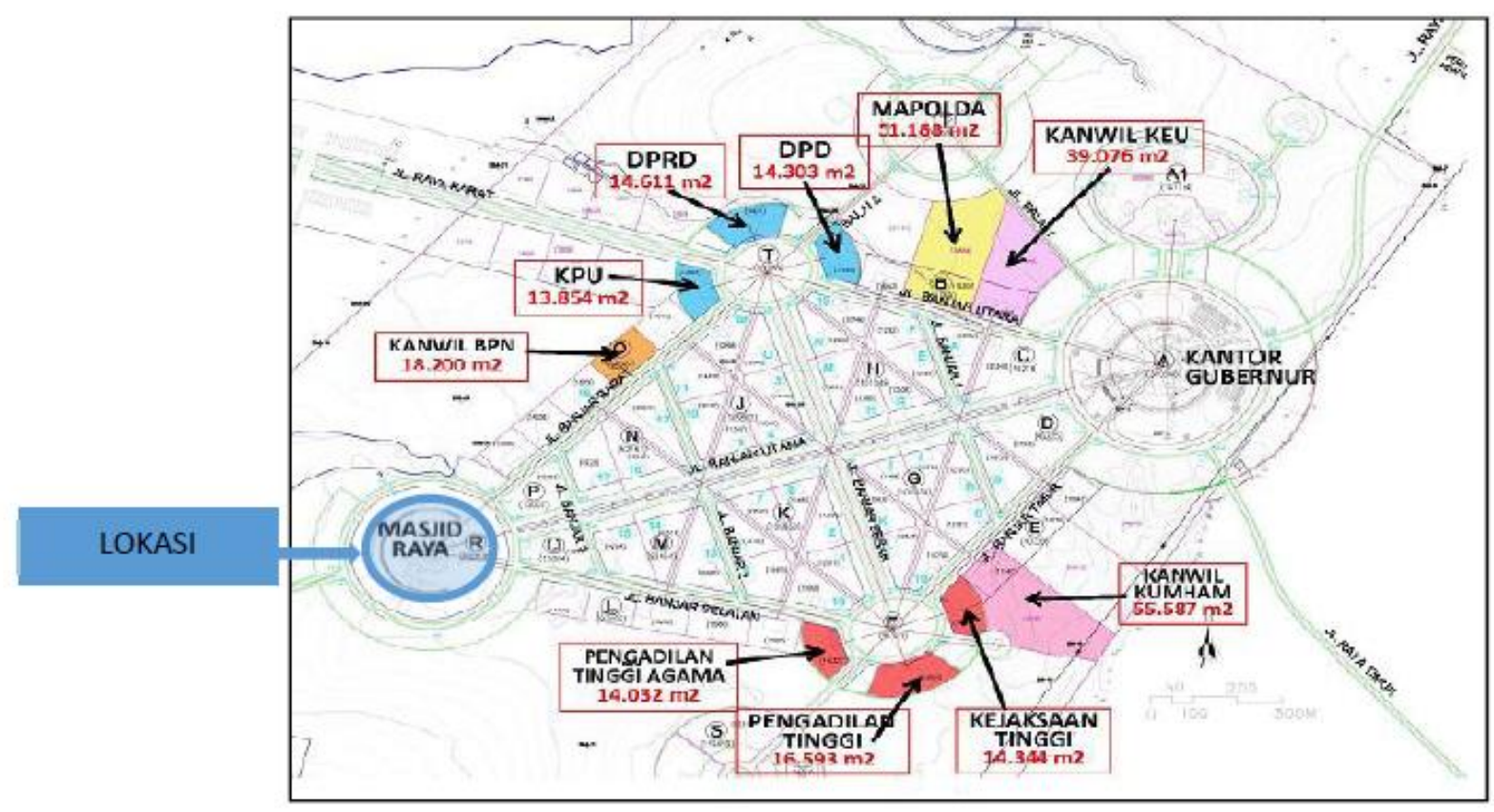

Gambar 1. Lokasi Pembangunan Masjid Agung

Sumber Gambar: Dokumen Sayembara Masjid Agung Pemprov Kalimantan Selata

\section{Pengolahan Data}

Pengolahan data mencakup aspek teknis, yaitu

a. Perhitungan Kebutuhan Air Bersih

Perhitungan kebutuhan air bersih berdasarkan pemakaian air dalam 1 hari

$\mathrm{Qd}=$ kapasitas jamaah $\mathrm{x}$ pemakaian air per orang perhari

b. Perhitungan Curah Hujan Efektif

Perhitungan curah hujan efektif dapat dilakukan dengan metode Harza, yang menetapkan curah hujan efektif berdasarkan rangking pada urutan ke-n dari harga terkecil curah hujan 10 tahunan, dengan menggunakan rumus dasar:

$\mathrm{n}=(\mathrm{N} / 5)+1$

Dimana:

$\mathrm{n}=$ nomer urut yang terpilih (bilangan bulat)

$\mathrm{N}=$ jumlah data

c. Perhitungan Curah Hujan yang Dapat Ditampung

Berdasarkan pemilihan curah hujan efektif yang didapat, serta rencana luas atap bangunan maka dapat dilakukan perhitungan terhadap curah hujan yang dapat ditampung untuk kawasan Masjid Agung Banjarbaru. Perhitungan curah hujan yang dapat ditampung dapat dilihat pada persamaan (1)

$\mathrm{S}=\mathrm{A} \times \mathrm{M} \times \mathrm{F}$

Dimana:

$\mathrm{S}=$ supply air hujan yang diterima $\left(\mathrm{m}^{3}\right)$

$\mathrm{A}=$ luas area penangkapan air hujan $\left(\mathrm{m}^{2}\right)$

$\mathrm{M}=$ curah hujan rata-rata $(\mathrm{mm} / \mathrm{bulan} / \mathrm{harian})$

$\mathrm{F}=$ koofisien pengairan atau run-off 
d. Perhitungan Kapasitas Kolam Penampungan Air Hujan

Perhitungan kapasitas kolam penampungan air hujan dapat dilakukan setelah menghitung debit curah hujan yang ditampung dan jumlah kebutuhan air bersih. Hasil perbandingan keduanya akan menentukan apakah volume curah hujan dapat memenuhi kebutuhan air bersih pada lokasi penelitian.

\section{HASIL DAN PEMBAHASAN}

\section{Analisa Kebutuhan Air Bersih}

Dengan ketentuan standar kebutuhan air bersih non domestik untuk masjid adalah 20-40 liter/orang/hari. Sehingga perhitungan kebutuhan air bersih dengan kapasitas maksimal masjid sejumlah 1500 jamah adalah:

$\mathrm{Qd}=$ kapasitas jamaah $\mathrm{x}$ pemakaian air per orang perhari

$=1500 \times 30$ liter/hari

$=45.000$ liter $/$ hari $=45 \mathrm{~m}^{3}$

Dari perhitungan di atas didapatkan kebutuhan airbaku untuk keperluan jamaah dalam sebulan adalah: 45 x $30=1.350 \mathrm{~m}^{3}$

\section{Analisa Curah Hujan Efektif yang Dapat Ditampung}

Data curah hujan berasal dari Stasiun Banjarbaru, karena merupakan stasiun hujan terdekat dari kawasan pembangunan Masjid Agung. Data curah hujan ditunjukkan pada Tabel 1.

Tabel 1. Data Curah Hujan Tabel Kota Banjarbaru Tahun 2005-2014

\begin{tabular}{|c|c|c|c|c|c|c|c|c|c|c|}
\hline \multirow[t]{2}{*}{ Bulan } & \multicolumn{10}{|c|}{ Tahun } \\
\hline & 2005 & 2006 & 2007 & 2008 & 2009 & 2010 & 2011 & 2012 & 2013 & 2014 \\
\hline Januari & 286.9 & 362.6 & 240.6 & 221.7 & 384 & 324.3 & 418.9 & 223.7 & 355.2 & 443 \\
\hline Februari & 271.8 & 345.9 & 239 & 242 & 148 & 320.6 & 211.8 & 258.4 & 414.6 & 220 \\
\hline Maret & 332.5 & 294.8 & 482.7 & 419.4 & 212 & 285.1 & 337.1 & 313 & 308.3 & 332 \\
\hline April & 129.5 & 219.3 & 325.6 & 228.5 & 279 & 243 & 250.8 & 319.1 & 305.5 & 223 \\
\hline Mei & 230.4 & 72.5 & 235.3 & 140.2 & 237 & 171 & 210.5 & 149.1 & 346.5 & 159 \\
\hline Juni & 49.7 & 188.2 & 170.9 & 170.1 & 22 & 365.7 & 83.1 & 58.4 & 140.7 & 221 \\
\hline Juli & 18.8 & 24.7 & 229.3 & 225.1 & 73 & 171.7 & 21.3 & 193.5 & 125.7 & 113 \\
\hline Agustus & 49.3 & 4.6 & 54.8 & 157.6 & 25 & 240.4 & 26.8 & 70.3 & 81.5 & 53 \\
\hline September & 36.1 & 2.9 & 30.1 & 127.5 & 21 & 338.2 & 77.3 & 58.2 & 33.6 & 5 \\
\hline Oktober & 176.5 & 16.5 & 62.4 & 208.8 & 189 & 256.5 & 133.5 & 157 & 106 & 16 \\
\hline Nopember & 203.2 & 115.6 & 1641.9 & 300.2 & 292 & 317.5 & 276.4 & 297.8 & 439.1 & 199 \\
\hline Desember & 284.4 & 408.4 & 255.2 & 427.2 & 287 & 354.7 & 856.4 & 409.8 & 349.4 & 387 \\
\hline Rata CH/Bln & 172.43 & 171.33 & 330.65 & 239.03 & 180.75 & 282.39 & 241.99 & 209.03 & 250.51 & 197.58 \\
\hline
\end{tabular}

Sumber: Hasil analisis dan BMKG 


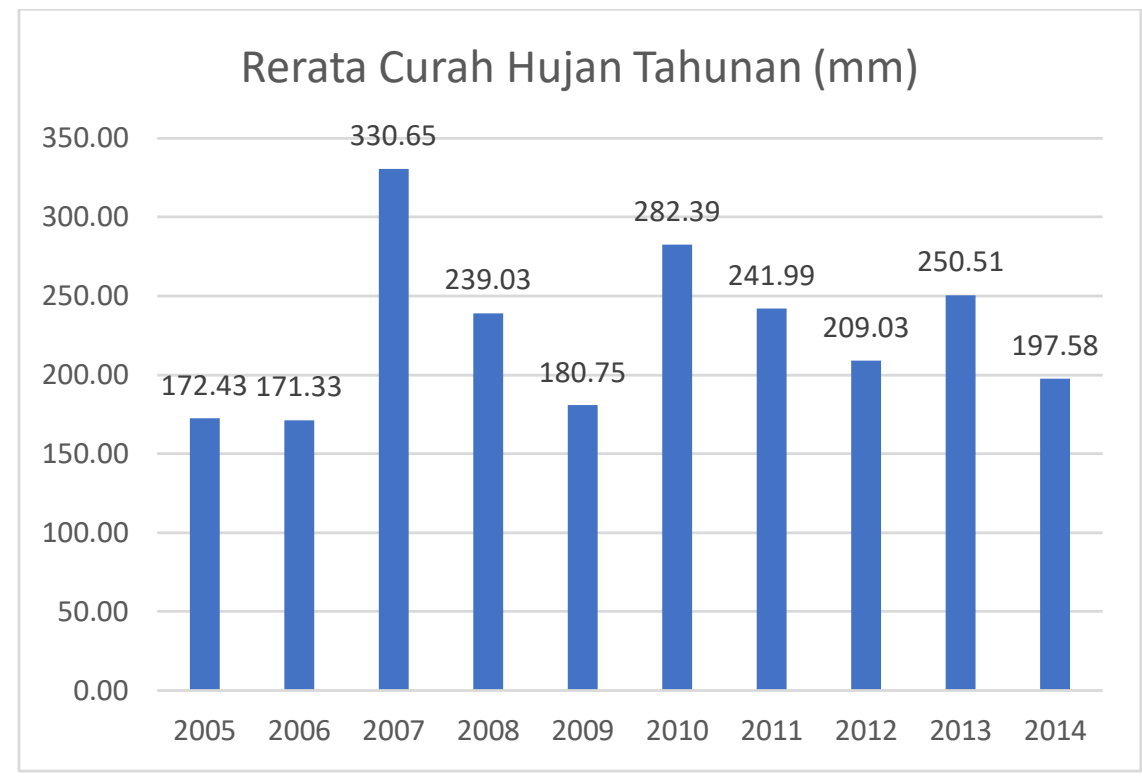

Gambar 2. Grafik Rerata Curah Hujan Tahunan

Sumber: Hasil analisis dan BMKG

Dari data curah hujan yang ada, maka untuk mendapatkan curah hujan efektif adalah dengan mengurutkan data dari yang terkecil hingga yang terbesar sehingga diperoleh hasil seperti pada tabel 2.

Tabel 2. Urutan Data Curah Hujan Maksimum Kota Banjarbaru Tahun 2005-2014 dari yang Terkecil

\begin{tabular}{cc}
\hline TAHUN & $\begin{array}{c}\text { CURAH } \\
\text { HUJAN (MM) }\end{array}$ \\
\hline 2006 & 171.33 \\
\hline 2005 & 172.43 \\
\hline 2009 & 180.75 \\
\hline 2014 & 197.58 \\
\hline 2012 & 209.03 \\
\hline 2008 & 239.03 \\
\hline 2011 & 241.99 \\
\hline 2013 & 250.51 \\
\hline 2010 & 282.39 \\
\hline 2007 & 330.65 \\
\hline
\end{tabular}

Sumber: Hasil analisis dan BMKG 


$$
\begin{aligned}
& \text { Dengan menggunakan persamaan (1) maka di dapat: } \\
& \begin{aligned}
\mathrm{n} & =(\mathrm{N} / 5)+1 \\
& =(10 / 5)+1 \\
& =3 \text { (urutan data yang diambil) }
\end{aligned}
\end{aligned}
$$

Selanjutnya hasil perhitungan diatas akandijadikan pedoman dalam menghitung supply curah hujan pada perencanaan ini.Data yang diambil adalah curah hujan di tahun 2009 sejumlah 180.75 mm. Untuk mengetahui supply curah hujan pada perencanaan ini, sebelumnya harus diketahui luasan atap yang akan digunakan untuk menampung curah hujan yang ada. Tabel 2 merupakan perhitungan total keseluruhan luas atap.

Tabel 2. Luasan Atap Bangunan

\begin{tabular}{clccc}
\hline No. & \multicolumn{1}{c}{ Nama Bangunan } & $\begin{array}{c}\text { Jumlah } \\
\text { Bangunan }\end{array}$ & $\begin{array}{c}\text { Luasan Atap } \\
\left(\mathbf{m}^{2}\right)\end{array}$ & $\begin{array}{c}\text { Total Luasan } \\
\mathbf{A t a p}_{\left(\mathbf{m}^{2}\right)}\end{array}$ \\
\hline $\mathbf{1}$ & Bangunan Utama & 1 & 10.000 & 10.000 \\
\hline $\mathbf{2}$ & $\begin{array}{l}\text { Bangunan Kantor/Dewan } \\
\text { Kemakmuran }\end{array}$ & 8 & 150 & 1.200 \\
& $\begin{array}{l}\text { Masjid/Perpustakaan/Koperasi } \\
\mathbf{3}\end{array}$ & & & \\
\hline & Bangunan Wudhu/KM & 6 & 200 & 1.200 \\
\hline
\end{tabular}

Sumber: Hasil Desain dan Analisa

Dengan menggunakan persamaan (2) maka akan didapatkan jumlah supply air hujan yang akan diterima dengan total luasan atap yang tercantum pada tabel 1.3. adalah:

$\mathrm{Q}$ supply $=\mathrm{A} \times \mathrm{C} \times \mathrm{h}$

$=12.400 \times 0,8 \times 0,180$

$=1.785,60 \mathrm{~m}^{3}$

Dimana:

Qsupply = supply air hujan yang diterima $\left(\mathrm{m}^{3}\right)$

$\mathrm{A}=$ luas area penangkapan air hujan $\left(\mathrm{m}^{2}\right)$

$\mathrm{h}=$ curah hujan rata-rata (efektif) $(\mathrm{m} /$ harian)

$\mathrm{C}=$ koofisien limpasan (run-off), diambil 0,8 untuk penutup atap jenis logam.

\section{Analisa Kapasitas Kolam Penampungan Air Hujan}

Berdasarkan perbandingan antara suplai air hujan dan kebutuhan air baku Vsupply> Vdemand. Sehingga air hujan masih bisa mencukupi untuk memenuhi kebutuhan air bakurata-rata jamaah Masjid Agung. Jadi kapasitas kolam Penampungan Air Hujan yang diijinkan harus melebihi Volume supply air hujan yang diterima oleh atap. Rencana kolam penampungan air hujan yang akan dibuat adalah 4 buah, sehingga agar dapat menampung debit air hujan yang diterima, maka masing-masing kolam harus dapat menampung debit air: Volume kolam $\mathrm{PAH}=1.785,60: 4=$ 446, $40 \mathrm{~m}^{3} / \mathrm{kolam}$.

\section{Analisa Konsep Perancangan}

Mengadopsi bangunan asli rumah tradisional daerah Kalimantan Selatan yang dinamakan "Rumah Bubungan Tinggi". Bubungan atap Rumah adat Kaimantan Selatan ini berbentuk segitiga dengan atap tinggi melancip (disebut dengan Bubungan Tinggi), memanjang ke depan (disebut dengan atap Sindang Langit) dan memanjang ke belakang (disebut atap Hambin Awan). Model atap rumah tradisional daerah Kalimantan Selatan dapat dilihat pada gambar 3. 


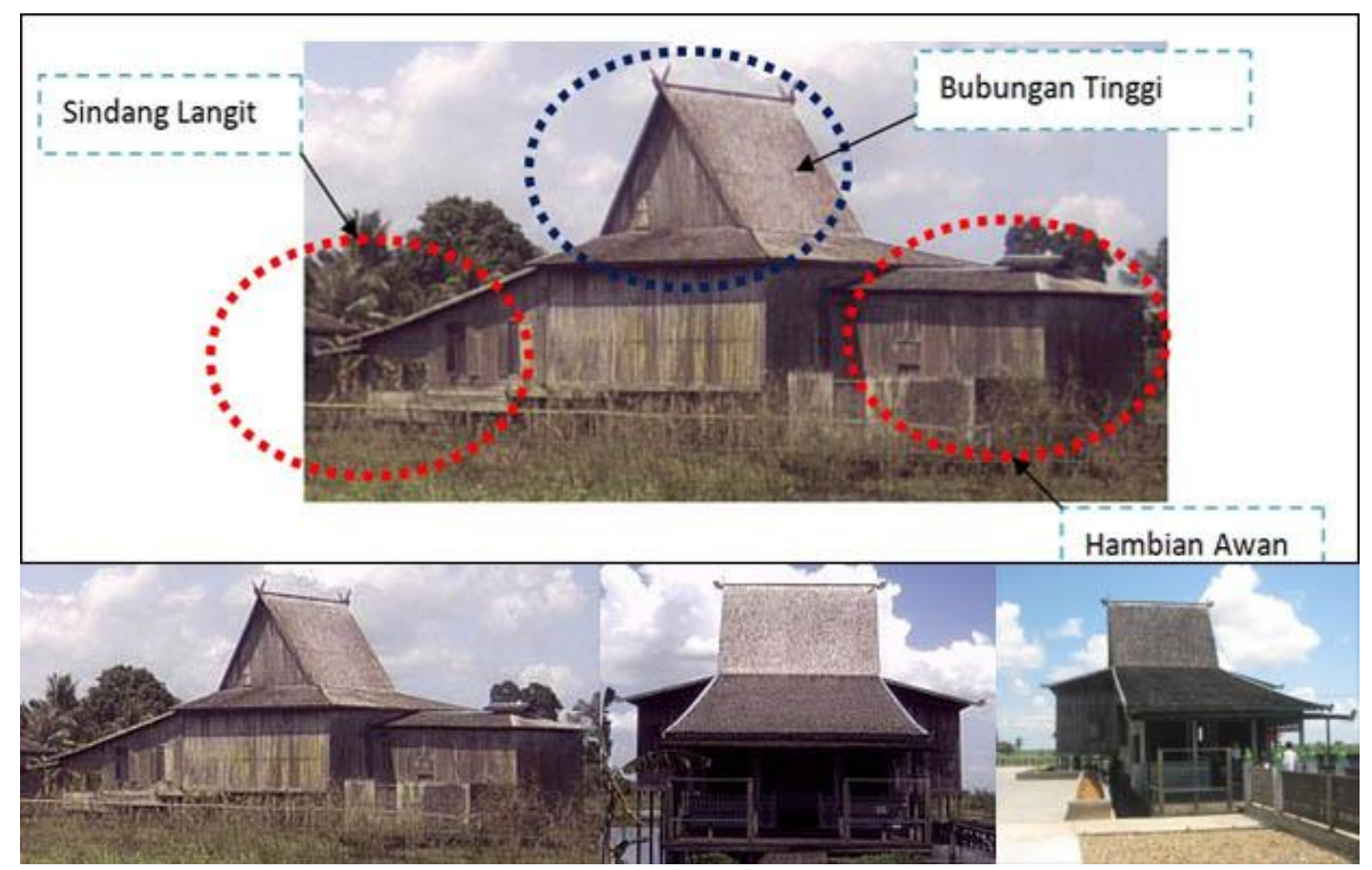

Gambar 3. Bentuk Atap Rumah Tradisional Daerah Kalimantan Selatan

Pada perencanaan masjid Agung Banjarbaru mempergunakan bentuk atap Bubungan Tinggi dan Sindang Langit seperti yang ditunjukkan pada gambar 4 di bawah ini.

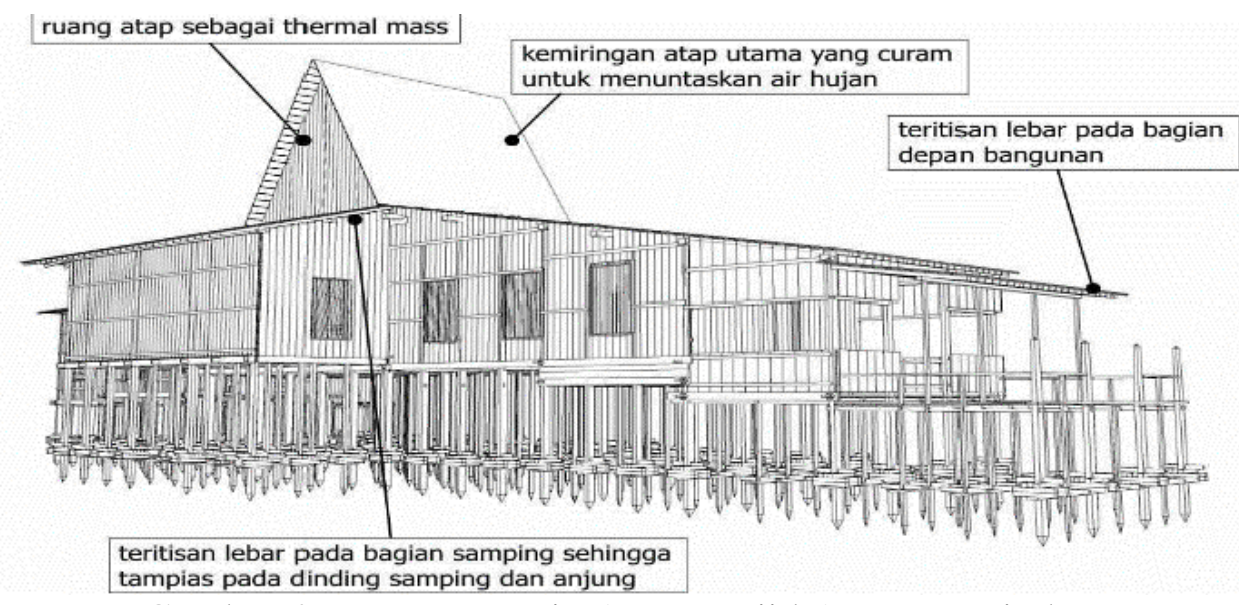

Gambar 4. Konsep Desain Atap Masjid Agung Banjarbaru

\section{Analisa Perancangan Pemanenan Air Hujan pada Desain Masjid Agung}

Dalam pemanenan air hujan melalui atau terdiri dari 3 elemen dasar yaitu area koleksi, system alat angkut dan fasilitas penyimpanan.Penerapan tersebut pada bangunan masjid Agung adalah sebagai berikut:

\section{Atap/Daerah Tangkapan Air Hujan (Catchment Area)}

Area koleksi pada bangunan Masjid Agung ini adalah bagian atap. Sudut atap atau kemiringan atap akan menentukan kecepatan di mana air akan meninggalkan daerah tangkapan air (catchment area). Atap yang curam akan menumpahkan air dengan cepat, bersamaan dengan pembuangan puing-puing atau bahan organik lainnya. Kemiringan yang lebih tinggi juga 
berkinerja lebih baik sebagai daerah tangkapan air dengan mencegah penumpukan air yang terhenti dan kemungkinan terkontaminasinya air yang akan mempengaruhi penyimpanan air. Bentuk atap yang dipakai adalah bentuk atap model "Bubungan Tinggi" dengan derajat kemiringan $45^{\circ}$ dengan tambahan atap model "Sindang Langit" dengan kemiringan atap $10^{\circ}$.

Material atap yang baik untuk untuk sistem pemanenan air hujan adalah aluminium atau baja zinc atau aluminium yang sudah dicat, namun dapat pula digunakan material atap genteng atau atap beton. Material atap yang digunakan pada bangunan masjid Agung ini adalah alumunium baja zinc yang dapat menghasilkan 50\% lebih banyak dari jenis material atap lainnya karena bentuknya flat atau landai (Sumber: European Commission DG ENV News Alert Issue 254,23 September 2011).

Bentuk atap hasil rancangan ditunjukkan dalam gambar 3 (tiga) dimensi pada gambar 5 dibawah ini.

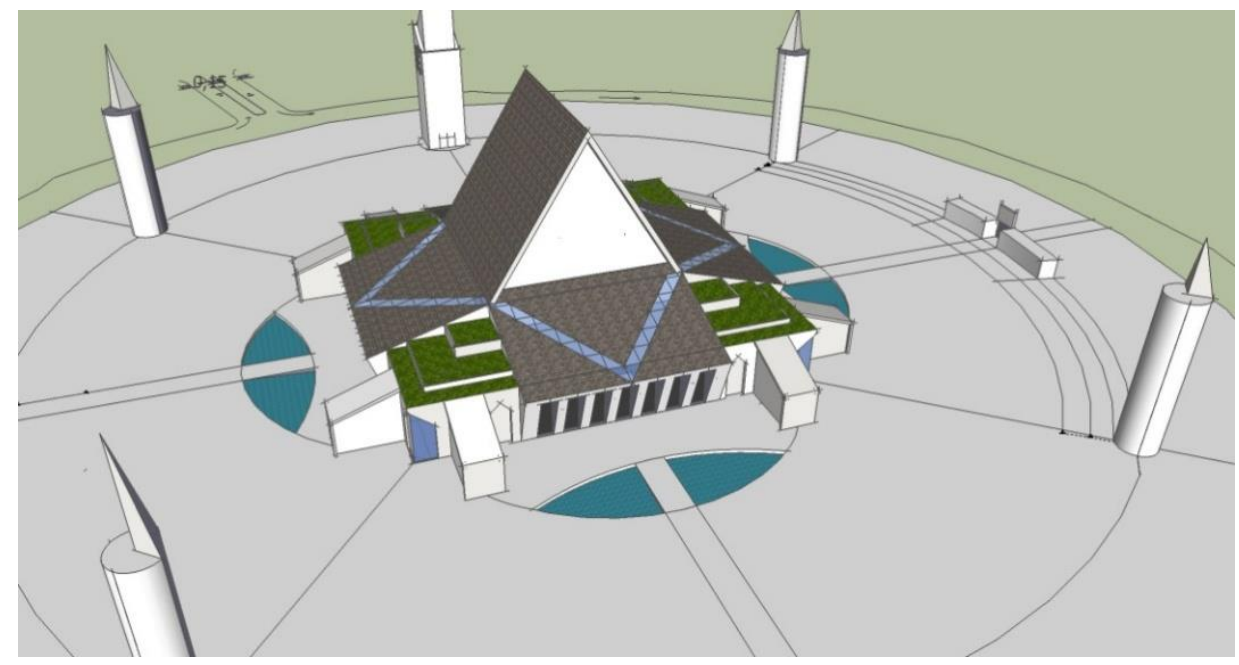

Gambar 5. Hasil Desain Bentuk Atap Masjid Agung

Denah rencana atap dan arah aliran air hujan yang jatuh dari daerah tangkapan hujan (atap), ditunjukkan pada gambar 6 di bawah ini.

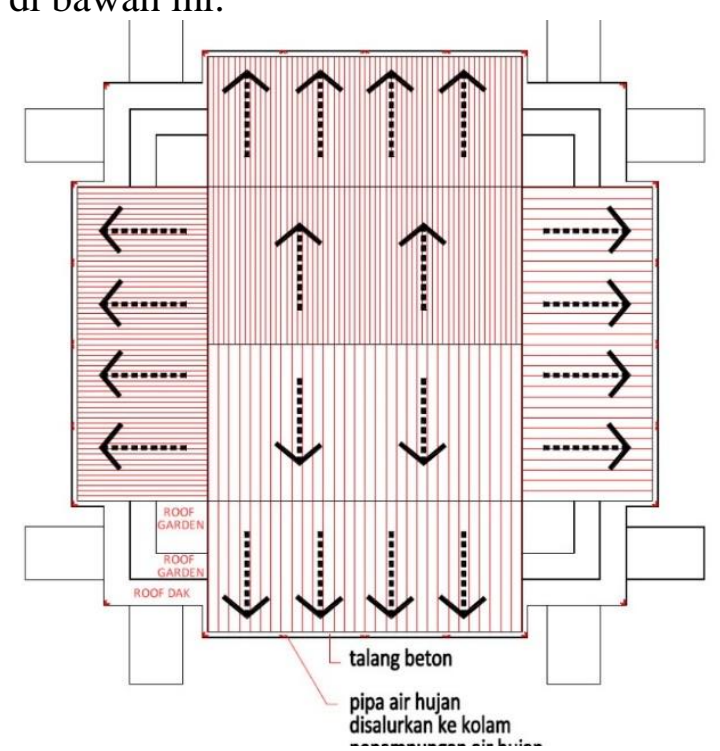

Gambar 6. Rencana Atap dan Pola Arah Aliran Hujan 


\section{Sistem Drainase Air Hujan}

Sistem drainase atau pengiriman air hujan dari permukaan atap ke wadah penyimpanan adalah dengan menggunakan talang dan pipa vertikal. Saat pemilihan talang dan pipa vertikal penting untuk mempertimbangkan 3 faktor yaitu ukuran, pemasangan yang tepat dan estetika.

Ukuran talang sebaiknya berukuran sedemikian rupa sehingga cukup memindahkan air hujan dengan intensitas tinggi. Sebagai aturan umum talang yang digunakan berukuran minimal $3-5$ inch.

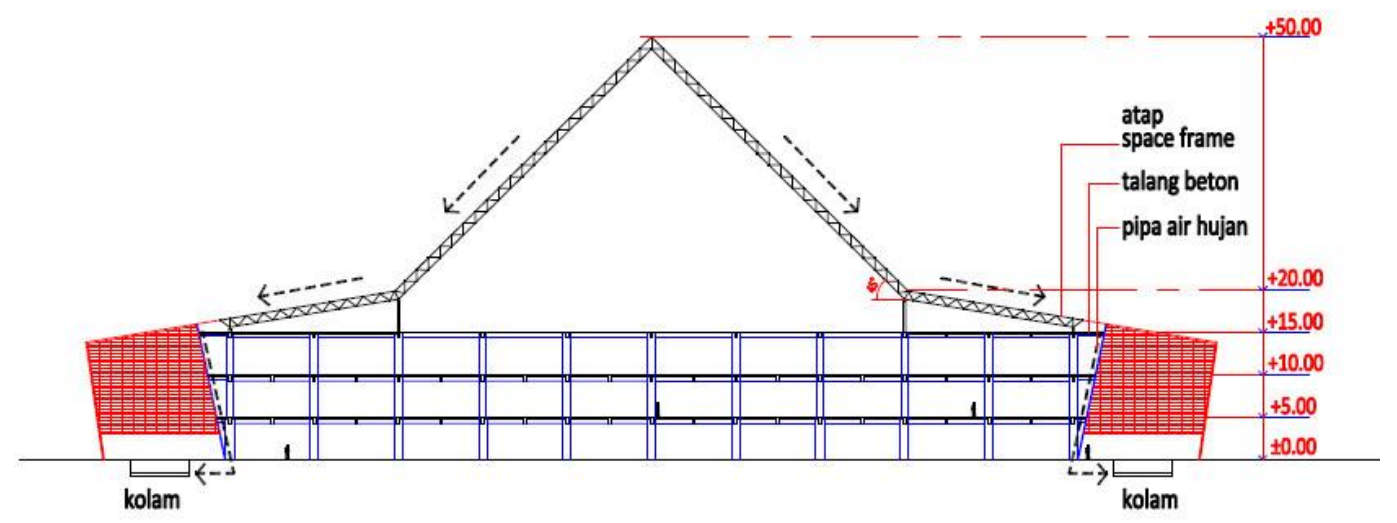

Gambar 7. Potongan Bangunan Utama Masjid

Ukuran pipa air vertikal yang digunakan dengan diameter 3 - 8-inch yang akan diteruskan ke tangki penyimpanan/reservoir. Pada rancangan, posisi pipa air vertikal diletakkan tersembunyi di dalam dinding fasade bangunan seperti terlihat pada gambar 8 .

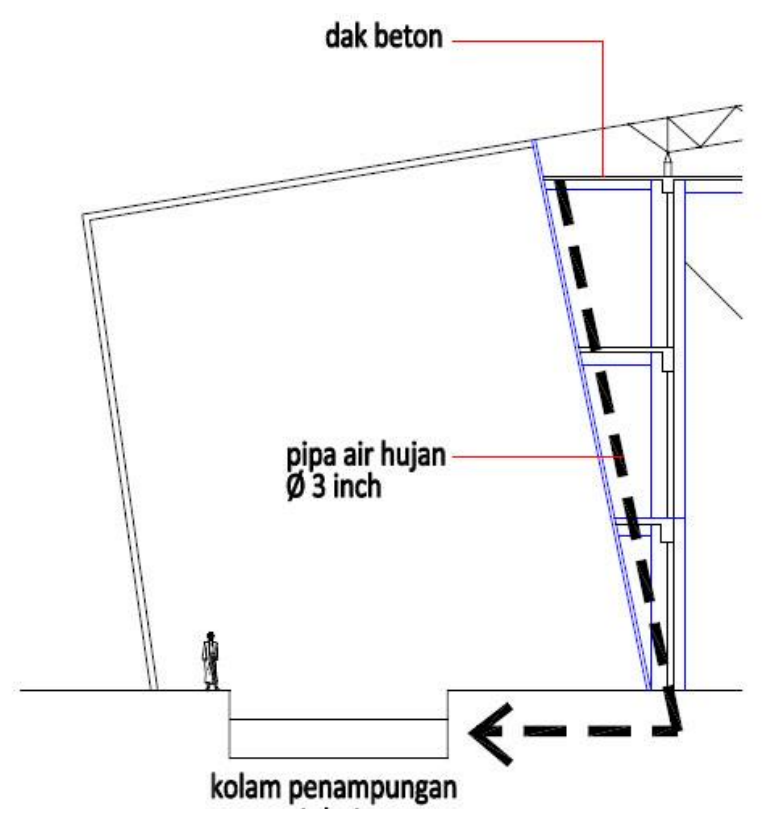

Gambar 8. Detail Perletakan Talang Air Vertikal pada Bangunan Utama 


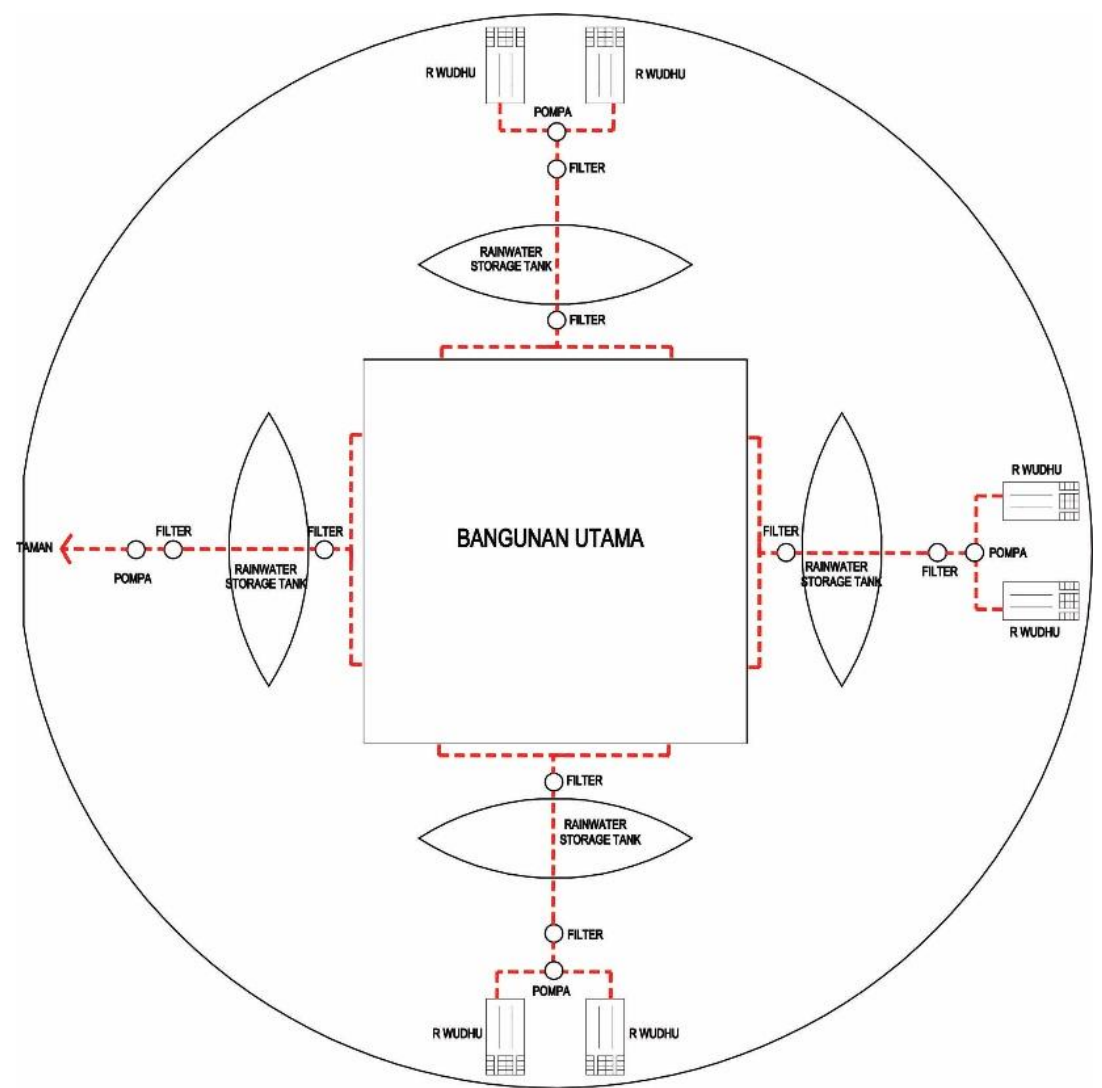

Gambar 9. Pola Jaringan Distribusi Air Hujan pada Tapak Bangunan

\section{Penyimpanan/Penampungan Air pada Reservoir}

Tangki penyimpanan atau kolam penampungan air hujan pada proyek penelitian ini terbuat dari bahan beton bertulang dengan finishing keramik yang dibangun terpisah dari bangunan utama. Bentuk kolam penampungan secara keseluruhan pada tapak dapat dilihat pada gambar 9.

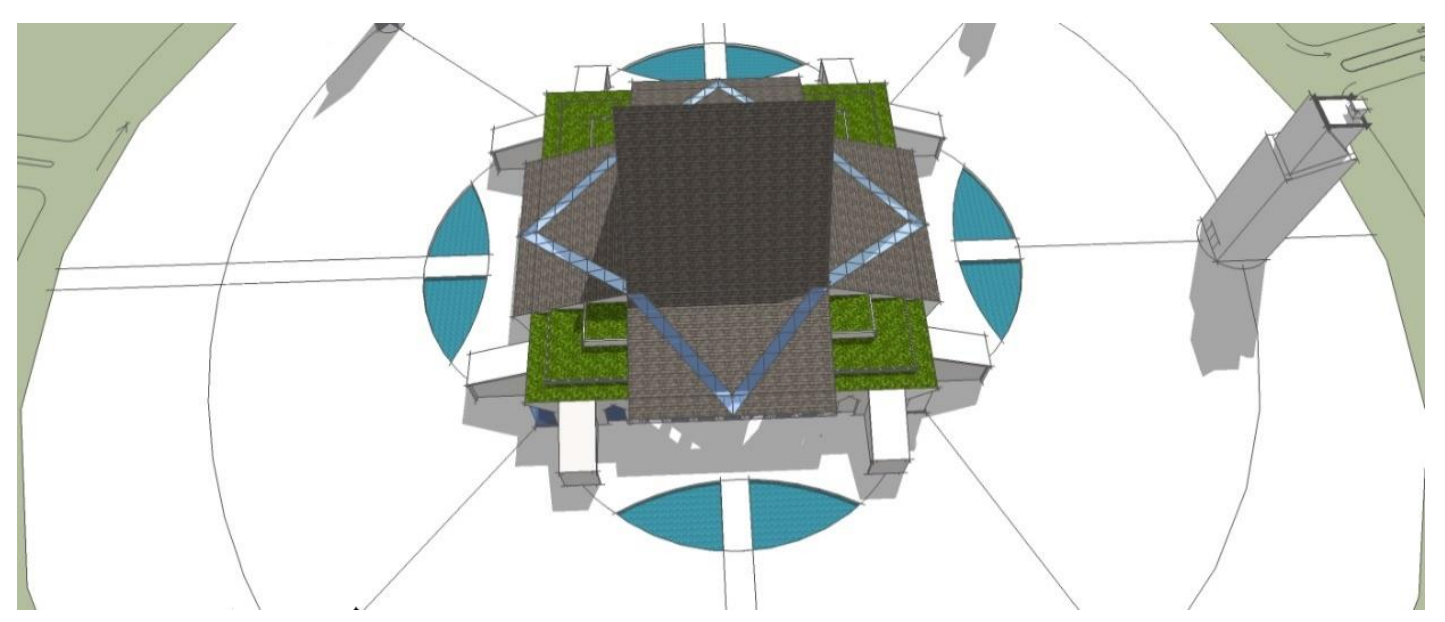

Gambar 10. Rancangan Kolam Pemanenan Air Hujan 
Rancangan kolam penampungan diletakkan di atas permukaan tanah dan berbentuk terbuka. Penampungan air hujan yang diletakkan di atas tanah mempunyai keuntungan dalam mengambil dan memanfaatkan airnya. Kolam ini selain berfungsi untuk menampung air hujan juga dapat sebagai penunjang elemen estetika bangunan utama.

Gambar detail kolam penampungan air hujan dapat dilihat pada gambar 10.

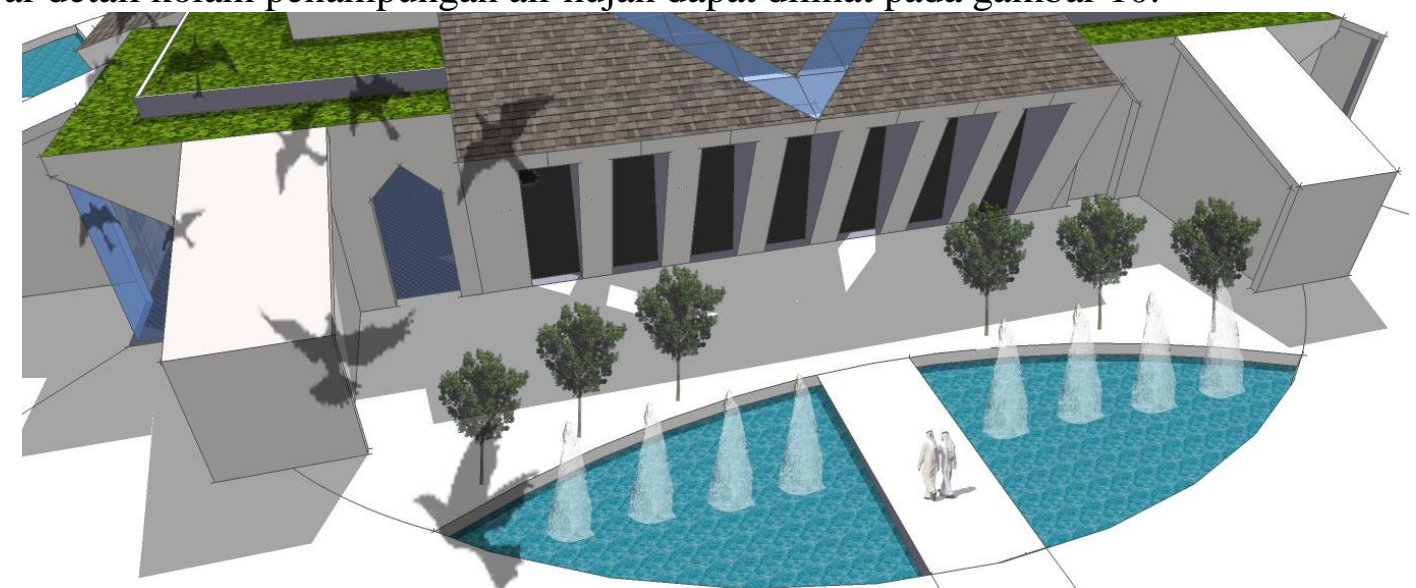

Gambar 11. Detail Rancangan Kolam Pemanenan Air Hujan

\section{KESIMPULAN DAN SARAN}

Dari perencanaan sistem penampungan air hujan pada Masjid Agung di kawasan Perkantoran Banjarbaru Kalimantan Selatan dapat disimpulkan beberapa hal antara lain:

a. Penerapan sistem Pemanenan Air Hujan pada Masjid Agung Banjarbaru Kalimantan Selatan sebagian besar menggunakan air hujan untuk memenuhi kebutuhan air baku sehari-hari. Dari perhitungan, volume air hujan yang diterima oleh atap jumlahnya lebih besar daripada volume kebutuhan air bakusetiap bulannya di Masjid Agung.

b. Kolam pemanenan air hujan yang direncanakan berjumlah 4 buah, masing-masing kolam diharapkan dapat menampung volume tampungan air hujan $>446,40 \mathrm{~m}^{3}$. Dari masingmasing kolam penampungan,air akan disalurkan ke dalam pipa yang di bagian ujung terdapat filter untuk menyaring sampah-sampah atau kotoran berukuran besar. Selain filter untuk berukuran besar, terdapat juga filter untuk kotoran berukuran lebih kecil. Setelah air mengalami penyaringan, lalu diteruskan masuk pompa untuk selanjutkan dapat dialirkan ke area wudhu dan KM/WC.

c. Untuk dapat menampung volume tampungan air hujan maka dihasilkan luas masing=masing kolam penampungan air hujan adalah $600 \mathrm{~m}^{2}$ dengan kedalaman kolam adalah $0,84 \mathrm{~m}$. Pada penelitian ini penulis memperkirakan maksimal volume kolam penampungan dapat menampung air hujan sebesar $500 \mathrm{~m}^{3}$.

Saran untuk penelitian ini adalah agar dapat diadakan penelitian tambahan terhadap kebutuhan sumber air bersih lain, selain air hujan untuk dapat memenuhi kebutuhan air bersih di saat musim-musim kemarau. Diharapkan adanya penelitian terhadap kelebihan air hujan yang berfungsi sebagai pengisian air tanah (ground water recharge) misalnya dengan perencanaan pembuatan sumur-sumur resapan pada wilayah penelitian. 


\section{Ucapan Terima Kasih}

Penulis mengucapkan terima kasih kepada Pemerintah Provinsi Kalimantan Selatan Dinas Pekerjaan Umum dan Penataan Ruang sebagai penyelenggara "Sayembara Desain Masjid Agung Kawasan Perkantoran Banjarbaru" dan atas ketersediaannya data-data pendukung dalam melengkapi penulisan jurnal ini.

\section{REFERENSI}

Dwivedi, Arun Kumar; Patil, Virendra B; Karankal, Amol B. (2013). "Rooftop Rain Water Harvesting for Groundwater Recharge in an Educational Complex". Global Journal of Researches in Engineering Civil and Structural Engineering, Volume 13 Issue 1 Version 1.0.

Maryono, Agus. (2014). Menangani Banjir, Kekeringan dan Lingkungan. Gadjah Mada University Press, Yogyakarta.

Oni, S.I; Ege, Emmanuel; Asenime, Charles; Oke, S.A. (2008). "Rainwater Harvesting Potential for Domestic Water Supply in Edo State". Indus Journal of Management \& Social Sciences, Vol.2, No. 2: 87-98.

O.I, Shittu; O.T, Okareh; A.O, Coker. (2015). "Development of rainwater harvesting technology for securing domestic water supply in Ibadan, Nigeria". International Research Journal of Engineering Science, Technology and Innovation (IRJESTI). Vol. 4(1) pp. 032-037.

Steffen, Jennifer; Jensen, Mark; Pomeroy, Christine A; Burian, Steven J. (2013). "Water Supply and Stormwater Management Benefits of Residential Rainwater Harvesting in U.S. Cities". Journal of The American Water Resources Association, Volume 49, No. 4.

Said, Nusa Idaman; Widayat, Wahyu. (2014). Pengisian Air Tanah Buatan, Pemanenan Air Hujan dan Teknologi Pengolahan Air hujan. BPPT Press, Jakarta. 